\title{
The AD 775 cosmic ray event shown in Beryllium-10 data from Antarctic Dome Fuji ice core
}

\author{
Fusa Miyake ${ }^{1}$, Asami Suzuki, Kimiaki Masuda \\ Solar-Terrestrial Environment Laboratory, Nagoya University, Nagoya, Japan \\ E-mail ${ }^{1}$ : fmiyake@stelab.nagoya-u.ac.jp
}

Kazuho Horiuchi

Faculty of Science and Technology, Hirosaki University, Hirosaki, Japan

\section{Hideaki Motoyama}

National Institute of Polar Research, Tokyo, Japan

\section{Hiroyuki Matsuzaki}

MALT, University Museum, University of Tokyo, Tokyo, Japan

Yuko Motizuki, Kazuya Takahashi, Yoichi Nakai

Nishina Center for Accelerator-Based Science, RIKEN, Wako, Japan

\begin{abstract}
Cosmogenic nuclides such as ${ }^{14} \mathrm{C}$ or ${ }^{10} \mathrm{Be}$ are produced by cosmic rays to the Earth. It is known that their concentration in tree rings or in ice cores record the past cosmic ray intensities. A large annual excursion in ${ }^{14} \mathrm{C}$ content from $\mathrm{AD} 774$ to $\mathrm{AD} 775$ was firstly found in Japanese tree rings. After that this event has been confirmed by several verifications using some other tree samples from all over the world. Also quasi decadal ${ }^{10} \mathrm{Be}$ concentration data in the Antarctic ice core show rapid increase around $\mathrm{AD} 775$. However, annual ${ }^{10} \mathrm{Be}$ variations have not been revealed. We measured ${ }^{10} \mathrm{Be}$ concentrations in the Antarctic Dome Fuji ice core with quasi-annual resolution for the period approximately from AD 763 to $\mathrm{AD} 794$, and found a clear ${ }^{10} \mathrm{Be}$ increase around AD 775 against a background variations. Since our quasi-annual ${ }^{10} \mathrm{Be}$ data and $\mathrm{Na}^{+}$ion data which obtained from the same ice core show similar variations, the background variation in ${ }^{10} \mathrm{Be}$ concentration is considered as a climatic noise. It is possible that the large ${ }^{10} \mathrm{Be}$ increase is occurred by the AD 775 cosmic ray event. This manuscript is based on our published paper, Miyake et al. [2015] to GRL.
\end{abstract}

Cosmogenic nuclide

AD 775 cosmic ray event

Dome Fuji ice core

The 34th International Cosmic Ray Conference

30 July- 6 August, 2015

The Hague, The Netherlands

${ }^{1}$ Speaker 


\section{Introduction}

Carbon-14 is one of the cosmogenic nuclides which is produced by incoming comic rays to the Earth. After ${ }^{14} \mathrm{C}$ is produced in the atmosphere, it becomes $\mathrm{CO}_{2}$ and is mixed with other $\mathrm{CO}_{2}$ in the atmosphere uniformly. They also diffuse into the marine and the biosphere through the global carbon cycle. Since a part of they are absorbed in trees, carbon-14 contents in tree rings would record information of a past cosmic ray intensity.

An annual cosmic ray increase event from AD 774 to AD 775, which is firstly found in Japanese cedar trees [Miyake et al. 2012, 2014], has been confirmed by the several ${ }^{14} \mathrm{C}$ content measurements of tree samples from Germany [Usoskin et al. 2013], North America [Jull et al. 2014], Russia [Jull et al. 2014], and New Zealand [Güttler et al. 2015]. They all showed similar increments about $12 \sim 14 \%$ in ${ }^{14} \mathrm{C}$ content from $\mathrm{AD} 774$ to $\mathrm{AD} 775$. It is considered that this ${ }^{14} \mathrm{C}$ increment corresponds to a ${ }^{14} \mathrm{C}$ production rate of $1.3 \sim 2.2 \times 10^{8}$ atoms $/ \mathrm{cm}^{2} / \mathrm{yr}$ [Usoskin et al. 2013, Pavlov et al., 2013, Miyake et al. 2014, Güttler et al. 2015] which is about several times larger than a normal ${ }^{14} \mathrm{C}$ production rate by galactic cosmic rays.

Also similar but a bit small annual ${ }^{14} \mathrm{C}$ increase ( 9\%) was found from AD 993 to AD 994. Although this event has been reported as ${ }^{14} \mathrm{C}$ measurements using only two Japanese trees, their measurements were completely independent [Miyake et al. 2013, 2014].

Some possible causes of these cosmic ray events have been proposed, which are a nearby supernova [Miyake et al. 2012], a short gamma-ray burst [Hambaryan and Neuhäuser 2013, Pavlov et al. 2013], a cometary impact on the Earth [Liu et al. 2014], and an extreme Solar Proton Event: SPE (or a sequence of SPEs) [Usoskin and Kovaltsov 2012, Eichler and Mordecai 2012, Usoskin et al. 2013, Melott and Thomas 2012, Thomas et al. 2013, Cliver et al. 2014]. In these causes, the nearby supernova and the commentary impact are unlikely as the causes because supernova remnants correspond to the two events have not been detected [Miyake et al. 2012, Hambaryan and Neuhäuser 2013], and it is not sufficient to explain an amount of the ${ }^{14} \mathrm{C}$ increase only by a commentary impact [Usoskin and Kovaltsov 2014].

Pavlov et al. [2013] showed that the short gamma ray burst origin produced an insufficient number of ${ }^{10} \mathrm{Be}$ atoms to detect. Then it is possible that ${ }^{10} \mathrm{Be}$ data become a key to specify a cause of the cosmic ray events. Berylium-10 is also a cosmogenic nuclide, and is deposited in ice sheets in the polar region. It is well known that ${ }^{10} \mathrm{Be}$ concentrations in ice cores from Antarctica and Greenland would record past cosmic ray intensity as ${ }^{14} \mathrm{C}$ contents in tree rings [Beer et al. 2012, Usoskin 2013]. Several studies have reported a good correlation between decadal ${ }^{14} \mathrm{C}$ data and ${ }^{10}$ Be data for the Holocene [Beer et al. 1988, Bard et al. 1997, Finkel and Nishiizumi 1997, Vonmoos et al. 2006, Horiuchi et al. 2008, Usoskin et al. 2009, Delaygue and Bard 2011, Abreu et al. 2013, Steinhilber et al. 2012, Adolphi et al. 2014, Muscheler et al. 2014].

One of the previous studies of a decadal ${ }^{10} \mathrm{Be}$ measurement using the Antarctic Dome Fuji ice core showed a sharp peak during the periods correspond to two ${ }^{14} \mathrm{C}$ events [Horiuchi et al. 2008]. Although these ${ }^{10} \mathrm{Be}$ sharp peaks are possible to be the two annual cosmic ray events, it is necessary to conduct a quasi-annual ${ }^{10} \mathrm{Be}$ measurement to identify these annual events.

We will report the result of ${ }^{10} \mathrm{Be}$ concentration measurements using the Dome Fuji ice cores which are the counterparts of those used for the previous quasi-decadal ${ }^{10} \mathrm{Be}$ measurements by Horiuchi et al. [2008]. We will also compare our ${ }^{10} \mathrm{Be}$ result with $\mathrm{Na}^{+}$ion data [Motizuki et al. 
2015] from the same ice core to discuss a climatic effect on a ${ }^{10} \mathrm{Be}$ deposition. This manuscript (method, result and discussion) is based on our published paper [Miyake et al. 2015].

\section{Methods}

\subsection{Sample and pretreatments}

We used Dome Fuji ice cores from central Antarctica ( $77^{\circ} 19^{\prime} \mathrm{S}, 39^{\circ} 42^{\prime} \mathrm{E}, 3810 \mathrm{~m}$ asl), which were stored in a freezer of the National Institute of Polar Research. We chose three ice core sections whose dates correspond to before and after the sharp increase shown in the previous quasi-decadal ${ }^{10} \mathrm{Be}$ measurements [Horiuchi et al. 2008]. The selected cores were cut in intervals of $\sim 3 \mathrm{~cm}$ (corresponds approximately to 1 year). The typical average mass of each cut piece is $23 \mathrm{~g}$.

Figure 1 shows a flow chart of a chemical pretreatments for our ${ }^{10} \mathrm{Be}$ measurement. An essence of the pretreatment methods are described in Horiuchi et al. [2007].

\begin{tabular}{|c|c|c|c|c|c|}
\hline $\begin{array}{l}\text { Melting of each ice } \\
\text { core sample at } \\
\text { room temperature }\end{array}$ & $\begin{array}{l}\text { Addition of }{ }^{9} \mathrm{Be} \\
\text { carrier solution to } \\
\text { samples }\end{array}$ & $\begin{array}{c}\text { Separation of }{ }^{10} \mathrm{Be} \\
\text { ion by ion } \\
\text { exchange } \\
\text { separation }\end{array}$ & $\begin{array}{c}\text { Formation of } \\
\text { precipitate } \\
\left(\mathrm{Be}(\mathrm{OH})_{2}\right) \text { by } \\
\text { adding } \mathrm{NH}_{3} \text { aqua }\end{array}$ & $\begin{array}{c}\text { Washing } \mathrm{Be}(\mathrm{OH})_{2} \\
\text { with deionized } \\
\text { water }\end{array}$ & $\begin{array}{c}\text { Converting } \\
\mathrm{Be}(\mathrm{OH})_{2} \text { into } \mathrm{BeO} \\
\text { by heating in } \\
\text { microwave crucible }\end{array}$ \\
\hline
\end{tabular}

Figure 1: Flow chart of our pretreatment methods. The ${ }^{9} \mathrm{Be}$ carrier solution and the $\mathrm{NH}_{3}$ aqua are Wako products.

\subsection{AMS measurement}

After we obtained $\mathrm{BeO}$, we prepared measurement-ready samples by mixing $\mathrm{BeO}$ with $\mathrm{Nb}$ powder (BeO: $\mathrm{Nb} \sim 1: 1.2$ ) and pressing into cathodes. The ${ }^{10} \mathrm{Be} /{ }^{9} \mathrm{Be}$ ratio was measured at a $5 \mathrm{MV}$ accelerator mass spectrometer at the University of Tokyo [Matsuzaki et al. 2007]. We calibrated the measured results using a standard material KNB5-2 (nominal ratio: $8.56 \times 10^{-13}$ ) [Nishiizumi et al. 2007].

\section{Results and Discussions}

\subsection{Periodic variation}

Figure 2 (a) shows our measured result. The horizontal line represents a ${ }^{14} \mathrm{C}-{ }^{10} \mathrm{Be}$ age which is determined by comparing a quasi-decadal ${ }^{10} \mathrm{Be}$ series and a decadal ${ }^{14} \mathrm{C}$ series [Horiuchi et al. 2008], and the vertical line represents the ${ }^{10} \mathrm{Be}$ concentration. We found a rapid and large ${ }^{10} \mathrm{Be}$ increase approximately from AD 778-780 in the ${ }^{14} \mathrm{C}_{-}{ }^{10} \mathrm{Be}$ age. Also there are periodic variations throughout this measurement period.

First, we consider about the periodic variation in ${ }^{10} \mathrm{Be}$ concentration. We performed a Fourier analysis on our ${ }^{10} \mathrm{Be}$ data, and got three periodic components of 2.8 years, 5.2 years and 8.2 years. Although there are a few previous studies about an annual ${ }^{10} \mathrm{Be}$ measurement in the Antarctica, Baroni et al. [2011] reported that there is a periodic variation of 3-7 years band in ${ }^{10} \mathrm{Be}$ concentration in the Antarctic Vostok ice core. They also pointed that the quasi-annual ${ }^{10} \mathrm{Be}$ data 
correlate with sodium ion $\left(\mathrm{Na}^{+}\right)$data which can reflect climatic information [Baroni et al. 2011]. We checked $\mathrm{Na}^{+}$ion data [Motizuki et al. 2015] from the same ice core we used for ${ }^{10} \mathrm{Be}$ analysis. Figure 2(b) shows the $\mathrm{Na}^{+}$concentration data. The two series of ${ }^{10} \mathrm{Be}$ and $\mathrm{Na}^{+}$show a good agreement $\left(\mathrm{R}^{2}=0.24, \mathrm{p}=0.0025\right)$, and this consistency is consistent with the result of Baroni et al. [2011] $\left(\mathrm{R}^{2}=0.26\right)$. From these results, it is possible that quasi-annual ${ }^{10} \mathrm{Be}$ data in most of Antarctica are reflected by climatic noises of a several years periodicity.

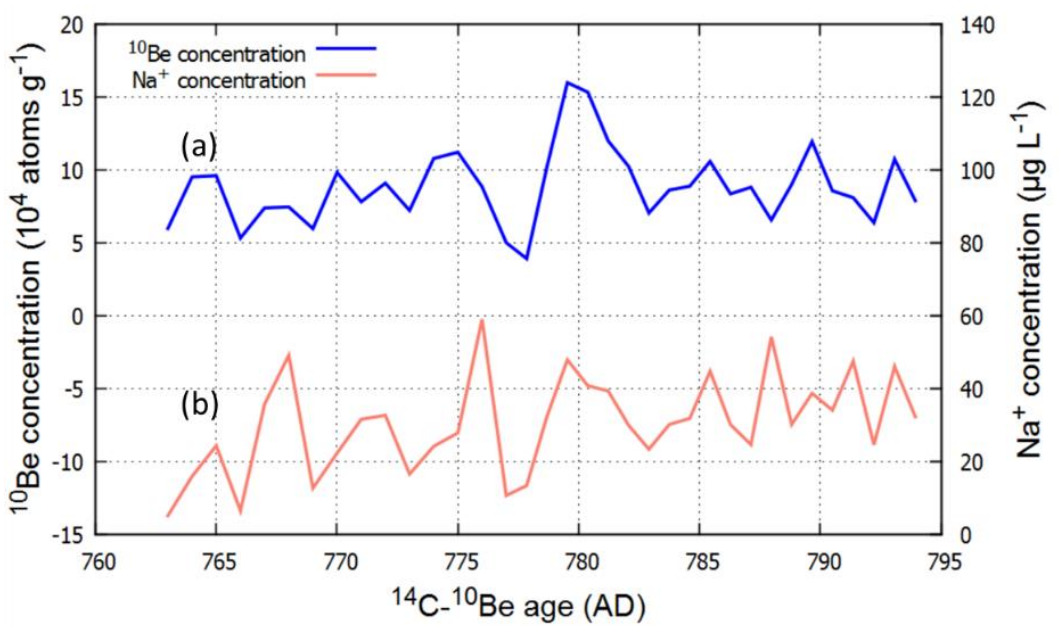

Figure 2: Comparison of the measured ${ }^{10} \mathrm{Be}$ concentration (a: present result) and $\mathrm{Na}^{+}$ion concentration (b: Motizuki et al. 2015) . This graph is cited from Miyake et al. [2015].

\subsection{Estimation of ${ }^{10} \mathrm{Be}$ increase}

Although the periodic variation in ${ }^{10} \mathrm{Be}$ concentration exists, the increase around $\mathrm{AD} 780$ is larger than the others. This increase is $80 \%$ from an average of all data (hereafter, we will call this event as the ${ }^{10} \mathrm{Be}$ event). However, the $\mathrm{Na}+$ ion data (which indicate the background variation) also increases at the same timing of an increase start point of the ${ }^{10} \mathrm{Be}$ event.

In order to find out how much increase the ${ }^{10} \mathrm{Be}$ event has against the background variations, we made a histogram of all increments of ${ }^{10} \mathrm{Be}$ data ( $\max -\min$ value) during the measurement periods. Figure 3 is the histogram of ${ }^{10} \mathrm{Be}$ increments, and the spread one shows the ${ }^{10} \mathrm{Be}$ event. According to the Thompson's rejection test, the ${ }^{10} \mathrm{Be}$ event obeys the probability of $1.2 \times 10^{-3}$ if we assume a normal distribution. This means the ${ }^{10} \mathrm{Be}$ event is outlier. On the other hand, an increase of $\mathrm{Na}^{+}$data which corresponds to the ${ }^{10} \mathrm{Be}$ event obeys the probability of $1.8 \times 10^{-1}$ by the same test. From these results, it is considered that the background variation during the ${ }^{10} \mathrm{Be}$ event is normal, and the ${ }^{10} \mathrm{Be}$ event is combined the background variation and the cosmic ray event.

However, it is difficult to estimate an accurate ${ }^{10} \mathrm{Be}$ increment (or ${ }^{10} \mathrm{Be}$ production rate) disturbed by the background variation. It will be necessary to conduct more annual ${ }^{10} \mathrm{Be}$ measurements and find a typical ${ }^{10} \mathrm{Be}$ background variations to confirm the increment of the ${ }^{10} \mathrm{Be}$ event with more precisely. 


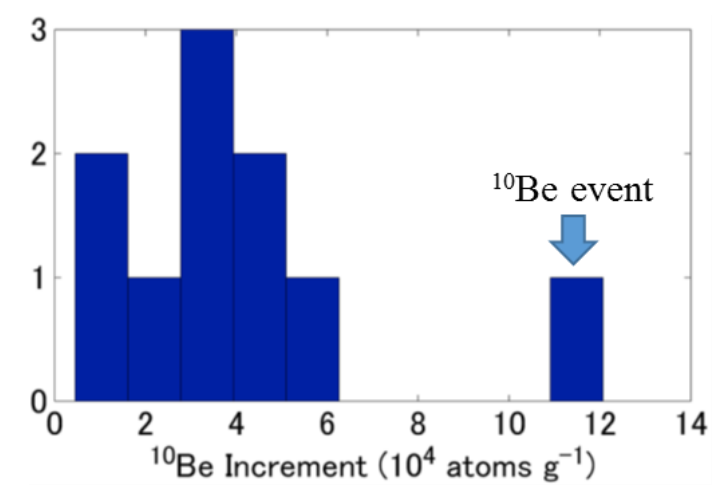

Figure 3: Histgram of the ${ }^{10} \mathrm{Be}$ increments. This graph is cited from Miyake et al. [2015].

\subsection{Cause of the AD 775 event}

As we mentioned in the introduction, the existence of the ${ }^{10} \mathrm{Be}$ increase corresponds to the AD 775 event indicates that the short gamma-ray burst origin is implausible. Miyake et al. [2013] pointed out that the occurrence of the ${ }^{14} \mathrm{C}$ event (AD 775 and AD 994) is much more frequently than the short gamma-ray burst rate, and the present result support this claim. For these reasons, the extreme SPE origin is a more plausible cause of the AD 775 event.

\section{Conclusions}

We measured quasi-annual ${ }^{10} \mathrm{Be}$ concentration in the Dome Fuji ice cores frorm the central Antarctica. We detected the distinct ${ }^{10} \mathrm{Be}$ increase from a background baseline during the period when the AD 775 cosmic ray event would be expected. We also found a periodic variation of 2.8-7.8 years during the present ${ }^{10} \mathrm{Be}$ data aside from the large ${ }^{10} \mathrm{Be}$ increase. It is considered that this variation is caused by a climatic valiability because of a consistency between ${ }^{10} \mathrm{Be}$ data and $\mathrm{Na}^{+}$ion data. Although a variation of an annual ${ }^{10} \mathrm{Be}$ data has yet to be elucidated fully, it is possible that such periodic background variations in ${ }^{10} \mathrm{Be}$ concentration exist for a long term, and we will need to consider such variation to discuss an existence of annual cosmic ray events.

The present result prefers the extreme SPE origin. In order to discuss an accurate ${ }^{10} \mathrm{Be}$ increase or ${ }^{10} \mathrm{Be}$ production rate, it will be necessary to conduct more quasi-annual ${ }^{10} \mathrm{Be}$ measurements.

\section{Acknoledgements}

We thank the Dome Fuji Ice Core Consortium for providing the ice core. We also thank M. Kitagawa and M. Igarashi for their help with obtaining the ion data. The work of F.M. was supported by a Research Fellowship of the Japan Society for the Promotion of Science (JSPS). The work of K.M. was supported by a Grant-in-Aid for Scientific Research (B) (grant 22340144) from JSPS. The workd of K.H.'s and H.M. was supported by a Grant-in-Aid for Scientific Research (A) (grants 22241003, 22244061, 25247082) from JSPS. The work of Y.M. was supported by Funding Program for Next Generation World-Leading Researchers (NEXT Program, grant GR098) by the Cabinet Office, Government of Japan and JSPS, and a Grant-inAid for Scientific Research (A) (grant 22244015) from JSPS. 


\section{References}

[1] J. A. Abreu, J. Beer, F. Steinhilber, M. Christl, and P. W. Kubik (2013), ${ }^{10}$ Be in ice cores and ${ }^{14} \mathrm{C}$ in tree rings: Separation of production and climate effects, Space Sci. Rev., 176, 343-349.

[2] F. Adolphi, et al., (2014), Persistent link between solar activity and Greenland climate during the Last Glacial Maximum, Nat. Geosci., 7, 662-666, doi:10.1038/ngeo2225.

[3] E. Bard, G. M. Raisbeck, F. Yiou, and J. Jouzel (1997), Solar modulation of cosmogenic nuclide production over the last millennium: Comparison between $14 \mathrm{C}$ and $10 \mathrm{Be}$ records, Earth Planet. Sci. Lett., 150, 453-462.

[4] M. Baroni, E. Bard, J. R. Petit, O. Magand, and D. Bourlès (2011), Volcanic and solar activity, and atmospheric circulation influences on cosmogenic ${ }^{10}$ Be fallout at Vostok and Concordia (Antarctica) over the last 60 years, Geochim. Cosmochim. Acta, 75, 7132-7145.

[5] J. Beer, et al., (1988), Information on past solar activity and geomagnetism from ${ }^{10}$ Be in the Camp Century ice core, Nature, 331, 675-679.

[6] J. Beer, K. McCracken, and R. von Steiger (2012), Cosmogenic Radionuclide Theory in the Terrestrial and Space Environments, Springer, Berlin.

[7] E. W. Cliver, A. J. Tylka, W. F. Dietrich, and A. G. Ling (2014), On a solar origin for the cosmogenic nuclide event of 775 A. D., ApJ, 781, 32, doi:10.1088/0004-637X/781/1/32.

[8] G. Delaygue, and E. Bard (2011), An Antarctic view of Beryllium-10 and solar activity for the past millennium, Clim. Dyn., 36, 2201-2218, doi:10.1007/s00382-010-0795-1.

[9] D. Eichler, and D. Mordecai (2012), Comet encounters and carbon 14, ApJ, 761, L27, doi:10.1088/2041-8205/761/2/L27.

[10] R. C. Finkel, and K. Nishiizumi (1997), Beryllium 10 concentrations in the Greenland Ice Sheet Project 2 ice core from 3-40 ka, J. Geophys. Res., 102, 26,699-26,706, doi:10.1029/97JC01282.

[11] D. Güttler, et al. (2015), Rapid increase in cosmogenic ${ }^{14} C$ in AD 775 measured in New Zealand kauri trees indicates short-lived increase in ${ }^{14}$ C production spanning both hemisphere, EPSL, $\mathbf{4 1 1}$, 290-297.

[12] V. V. Hambaryan, and R. Neuhäuser (2013), A Galactic short gamma-ray burst as cause for the ${ }^{14} \mathrm{C}$ peak in AD 774/5, Mon. Not. R. Astron. Soc., doi:10.1093/mnras/sts378.

[13] K. Horiuchi, et al. (2007), Concentration of ${ }^{10} \mathrm{Be}$ in an ice core from the Dome Fuji station, Eastern Antarctica: Preliminary results from 1500-1810 yr AD, Nucl. Instr. Meth. Phys. Res. B, 259, 584587.

[14] K. Horiuchi, et al. (2008), Ice core record of ${ }^{10}$ Be over the past millennium from Dome Fuji, Antarctica: A new proxy record of past solar activity and a powerful tool for stratigraphic dating, Quat. Geochronol., 3, 253-261.

[15] A. J. T. Jull, et al. (2014), Excursions in the ${ }^{14}$ C record at A.D. 774-775 in tree rings from Russia and America, Geophys. Res. Lett., 41, 3004-3010, doi:10.1002/2014GL059874.

[16] Y. Liu, et al. (2014), Mysterious abrupt carbon-14 increase in coral contributed by a comet, Sci. Rep., 4, 3728, doi:10.1038/srep03728.

[17] H. Matsuzaki, et al. (2007), Multi-nuclides AMS performances at MALT, Nucl. Instr. Meth. B, 259, $36-40$.

[18] A. L. Melott, and B. C. Thomas (2012), Causes of an AD $774-775^{14}$ C increase, Nature, 491, E1E2, doi:10.1038/nature11695. 
[19] F. Miyake, K. Nagaya, K. Masuda, and T. Nakamura (2012), A signature of cosmic-ray increase in AD 774-775 from tree rings in Japan, Nature, 486, 240-242.

[20] F. Miyake, K. Masuda, and T. Nakamura (2013), Another rapid event in the carbon-14 record of tree rings, Nat. Commun., 4, 1748, doi:10.1038/ncomms 2873.

[21] F. Miyake, et al. (2014), Verification of the cosmic ray event in AD 993-994 by using a Japanese Hinoki tree, Radiocarbon, 56, 1189-1194, doi:10.2458/56.17769.

[22] F. Miyake, et al. (2015), Cosmic ray event of A.D. 774-775 shown in quasi-annual ${ }^{10}$ Be data from the Antarctic Dom Fuji ice core, Geophys. Res. Lett., 42, doi:10.1002/2014GL062218.

[23] Y. Motizuki, et al. (2014), Dating of a Dome Fuji (Antarctica) shallow ice core by volcanic signal synchronization with B32 and EDML1 chronologies, Cryosphere Discuss., 8, 769-804.

[24] Y. Motizuki, et al. (2015), Chemical composition and unique characteristics of shallow ice core samples from a Dome Fuji core (Antarctica) drilled in 2001, submitted to International Journal of Environmental Analytical Chemistry.

[25] R. Muscheler, F. Adolphi, and A. Svensson (2014), Challenges in ${ }^{14} C$ dating towards the limit of the method inferred from anchoring a floating tree ring radiocarbon chronology to ice core records around the Laschamp geomagnetic field minimum, Earth Planet. Sci. Lett., 394, 209-215, doi:10.1016/j.eps1.2014.03.024.

[26] K. Nishiizumi, et al. (2007), Absolute calibration of ${ }^{10}$ Be AMS standards, Nucl. Instr. Meth. B, 258, 403-413.

[27] A. K. Pavlov, et al. (2013), AD 775 pulse of cosmogenic nuclide production as imprint of a Galactic gamma-ray burst, Mon. Not. R. Astron. Soc., 435, 2878-2884.

[28] F. Steinhilber, et al. (2012), 9,400 years of cosmic radiation and solar activity from ice cores and tree rings, Proc. Natl. Acad. Sci. U.S.A., 109, 5967-5971, doi:10.1073/pnas.1118965109.

[29] B. C. Thomas, A. L. Melott, K. R. Arkenberg, and B. R. Snyder II (2013), Terrestrial effects of possible astrophysical sources of an AD 774-775 increase in ${ }^{14} \mathrm{C}$ production, Geophys. Res. Lett., 40, 1237-1240, doi:10.1002/grl.50222.

[30] I. G. Usoskin, (2013), A history of solar activity over millennia, Living Rev. Sol. Phys., 10, 1, doi:10.12942/lrsp-2013-1.

[31] I. G. Usoskin, and G. A. Kovaltsov (2012), Occurrence of extreme solar particle events: Assessment from historical proxy data, ApJ, 757, 92, doi:10.1088/0004-637X/757/1/92.

[32] I. G. Usoskin, and G. A. Kovaltsov (2014), A comet could not produce the carbon-14 spike in the 8th century, Icarus, in press.

[33] I. G. Usoskin, K. Horiuchi, S. Solanki, G. A. Kovaltsov, and E. Bard (2009), On the common solar signal in different cosmogenic isotope data sets, J. Geophys. Res., 114, A03112, doi:10.1029/2008JA013888.

[34] I. G. Usoskin, et al. (2013), The AD775 cosmic event revisited: The Sun is to blame, Astron. Astrophys., 552, L3, doi:10.1051/0004-6361/201321080.

[35] M. Vonmoos, J. Beer, and R. Muscheler (2006), Large variations in Holocene solar activity: Constraints from 10Be in the Greenland Ice Core Project ice core, J. Geophys. Res., 111, A10105, doi:10.1029/2005JA011500. 